We do not attribute our patient's illness to his mother's illness, but there is a well-known association between immunological abnormality and malignancy. Several families have been described with a high incidence of Hodgkin's disease or lymphoma and immunological defect (Potolsky et al., 1971; Buehler et al., 1975). There must be a genetic basis for this combination of disorders in some families, although the occurrence of Hodgkin's disease in husband and wife (Mazar and Straus, 1951) suggests an environmental cause in others. In our case we believe that one genetic defect of immunity has predisposed to malignancy and immunological deficiency.

We thank Dr R. A. Thompson for immunoglobulin estimations and for supplying replacement gammaglobulin, and Dr S. Kumar for tests of lymphocyte markers. Miss V. Rawlinson kindly measured serum complement.

\section{References}

Buehler, S. K., Firme, F., Fodor, G., Fraser, G. R., Marshall, W. H., and Vaze, P. (1975). Common variable immune deficiency, Hodgkin's disease, and other malignancies in a Newfoundland family. Lancet, 1, 195-197.

Cooper, M. D., and Lawton, A. R. (1972). Circulating Bcells in patients with immunodeficiency. American Journal of Pathology, 69, 513-528.

Giedion, A., and Scheidegger, J. J. (1957). Kongenitale Immunoparese bei Fehlen spezifischer $\beta 2$-Globuline und quantitativ normale $\gamma$-Globulinen. Helvetica paediatrica acta, 12, 241-259.

Ipp, M. M., and Gelfand, E. W. (1976). Antibody deficiency and alopecia. Journal of Pediatrics, 89, 728-731.

Mazar, S. A., and Straus, B. (1951). Marital Hodgkin's disease. Archives of Internal Medicine, 88, 819-830.

Poliwoda, H., Stolte, H., Voth, H., Gothe, H. D., and Kostering, H. (1967). Lymphogranulomatose und Schwangerschaft. Archiv für klinische Medizin, 213, 255-277.

Potolsky, A. I., Heath, C. W., Jr, Buckley, C. E., III, and Rowlands, D. T. (1971). Lymphoreticular malignancies and immunologic abnormalities in a sibship. American Journal of Medicine, 50, 42-48.

Correspondence to Dr D. I. K. Evans, Royal Manchester Children's Hospital, Pendlebury, Manchester M27 1HA.

\title{
Intrapartum sensitisation of human infants to the Rhesus-D antigen
}

\author{
COLIN M. STERN \\ Department of Paediatrics and Neonatal Medicine, Hammersmith Hospital
}

SUMMARY A study is reported of the numbers of nonimmunoglobulin-bearing lymphocytes specifically binding to Rhesus-D positive erythrocytes in the blood of Rhesus-dd infants born to either Rhesus-dd or Rhesus-Dd mothers, at birth and at 6 months of age. There was a significant increase in the number of such antigen-binding cells by age 6 months in babies born to Rhesus-Dd mothers. It is concluded that the Rhesus-negative offspring of Rhesuspositive mothers may be sensitised against the Rhesus-D antigen at birth and that protection of such female infants by the injection of antiRhesus-D antibody should be considered.

The human infant at birth is capable of humoral antibody production against specific antigens. Although these responses are almost confined to immunoglobulin $\mathbf{M}$ (IgM) production, small amounts of immunoglobulin $\mathrm{G}$ ( $\mathrm{IgG}$ ) can be detected. Immune responses to most antigens require $T$ lymphocyte help and therefore the presence of specifically reacting $\mathrm{T}$-lymphocytes. The response to the Rhesus-D (Rh-D) antigen is thought to be of this kind.

Since the introduction of treatment with pooled antiRh-D antiserum for Rh-dd mothers postnatally, the incidence of haemolytic disease of the newborn has fallen dramatically. A few new patients are still found, usually ascribed either to the injection or infusion of Rh-incompatible blood or to a failure in treatment with antiRh-D antiserum (Woodrow, 1974). Some studies have suggested, intriguingly, that the birth of a Rh-dd infant to a Rh-Dd mother could lead to intrapartum sensitisation of the offspring, whose latent sensitivity might be reactivated many years later, during the gestation of a Rh-Dpositive fetus. Ramos de Almeida and Rosado (1972) found that the incidence of rhesus isoimmunisation by birth rank was dependent upon the grandmaternal Rh blood group, while Taylor (1967) and Hindemann (1973) suggest that sensitisation against Rh-D in infancy may be a significant event.

Some Rh-dd male infants, the offspring of either Rh-dd or Rh-Dd mothers, were selected by the Rh blood group and the ability of their peripheral blood 
lymphocytes to bind to Rh-D-positive erythrocytes at birth, and at 6 months, was studied.

\section{Materials and methods}

Blood samples were obtained from infants via the umbilical cord at birth and by venepuncture from the same infants at 6 months. The cells were purified by density centrifugation (Böyum, 1968) and washed 3 times in Eagle's minimal essential medium buffered with hepes (MEM-hepes). Indicator erythrocytes were either washed in MEM-hepes 3 times before use, or were first treated with a subagglutinating dose of $\mathrm{F}\left(\mathrm{ab}^{\prime}\right)_{2}$ (Nisonof et al., 1960) antiRh-D antiserum and then washed 3 times in MEM-hepes. Both preparations were made as $1 \%$ suspensions in MEMhepes. The indicator erythrocytes ${ }^{*}$ had been screened for a battery of red cell antigens and known to be positive only for Rh-D, although the presence of other blood group antigens could not be completely excluded.

Equal $50 \mu \mathrm{l}$ volumes of the lymphocyte suspension, at $2.5 \times 10^{9} / 1\left(2500 / \mathrm{mm}^{3}\right)$, and either indicator erythrocytes or indicator erythrocytes previously treated with antiRh-D antiserum, were mixed, centrifuged at $250 \mathrm{~g}$ for $7 \mathrm{~min}$ at room temperature, and incubated at $37^{\circ} \mathrm{C}$ for $30 \mathrm{~min}$. $50 \mu \mathrm{l}$ of MEMhepes containing fluorescein di-acetate (Bodmer et al., 1967) was added, and the numbers of fluorescent rosetted lymphocytes counted under a Leitz Ortholux fluorescent microscope. Control studies, in which lymphocytes had been pretreated with a $\mathrm{F}\left(\mathrm{ab}^{\prime}\right)_{2}$ antihuman immunoglobulin antiserum, showed that about $5 \%$ of rosettes were inhibited in this way, so that most antigen-binding cells (ABC) were nonimmunoglobulin-bearing and therefore were probably T-lymphocytes.

\section{Results and discussion}

The results in the Table show the numbers of Rh-Dspecific $A B C$ detected per $10^{6}$ lymphocytes. The values are derived by subtracting the numbers of rosettes formed after treatment of indicator erythrocytes with $F\left(a b^{\prime}\right)_{2}$ antiRh-D antiserum from the number of rosettes formed without erythrocyte pretreatment, leading to a number of negative values. Although no circulating $\mathrm{ABC}$ binding Rh-D antigen were found in cord blood at birth in either group of babies, by age 6 months 6 of 10 infants born to Rh-Dd mothers showed significant numbers of ABC and 2 more infants in the same group showed a smaller rise. Only 2 infants showed no increase in ABC. Three of 12 infants born to Rh-dd mothers demonstrated a small rise in $\mathrm{ABC}$.

*These were kindly provided by Professor P. L. Mollison.
Table Rhesus D antigen-specific rosettes per $10^{8} \mathrm{cells}$ formed by cord blood and peripheral blood lymphocytes from Rhesus D-negative infants of Rhesus D-positive and Rhesus D-negative mothers at birth and 6 months of age

\begin{tabular}{llllll}
\hline \multirow{2}{*}{$\begin{array}{l}\text { Sample } \\
\text { pair }\end{array}$} & \multicolumn{2}{l}{ Rosettes at birth } & & \multicolumn{2}{l}{ Rosettes at 6 months } \\
\cline { 2 - 3 } \cline { 5 - 5 } & $\begin{array}{l}\text { Mother } \\
\text { Rh-positive }\end{array}$ & $\begin{array}{l}\text { Mother } \\
\text { Rh-negative }\end{array}$ & $\begin{array}{l}\text { Mother } \\
\text { Rh-positive }\end{array}$ & $\begin{array}{l}\text { Mother } \\
\text { Rh-negative }\end{array}$ \\
\hline 1 & -1 & -3 & 291 & 31 \\
2 & 4 & -2 & 42 & -7 \\
3 & 3 & 2 & 59 & -6 \\
4 & -2 & -4 & 312 & 42 \\
5 & 0 & 2 & 218 & -4 \\
6 & -2 & 5 & 125 & -6 \\
7 & 2 & -3 & -11 & 6 \\
8 & -2 & 1 & 149 & -4 \\
9 & 3 & 5 & 5 & 15 \\
10 & -3 & -2 & 140 & 3 \\
11 & - & -3 & - & -3 \\
12 & - & 0 & - & -4 \\
\hline
\end{tabular}

Probability of

Not significant

Significant at $2 \%$ level difference between groups (WhitneyMann)

Values for both groups were compared by a Mann-Whitney U test (Mann and Whitney, 1947), which confirmed the similarity between the two groups at birth, but showed a difference, significant at the $2 \%$ level, between the two groups at 6 months. These results support the clinical evidence of the effect of the grand-maternal $\mathrm{Rh}$ blood group on the incidence of haemolytic disease of the newborn and provide evidence for the intrapartum sensitisation of Rh-dd newborn infants against the Rh-D antigen by transplacental haemorrhage from their Rh-Dd mothers. It may be that, if there is to be a reduction in the small number of mothers where the injection of antiRh-D antibody 'fails' to protect against $R h$ isoimmunisation, consideration should be given to the protection of Rh-dd infant girls born to Rh-Dd mothers by injection of antiRh-D antibody.

\section{References}

Bodmer, W. F., Tripp, M., and Bodmer, J. (1967). Application of fluorochromatic cytotoxic assay to human leukocyte typing. In Histocompatibility Testing, pp. 341-350. Edited by E. S. Curtoni, P. L. Mattiuz, and R. M. Tosi. Munksgaard: Copenhagen.

Böyum, A. (1968). Separation of leukocytes from bone marrow and blood. Scandinavian Journal of Clinical and Laboratory Investigation, 21, Supplement 97, 1-90.

Hindemann, P. (1973). Letter: Maternofetal transfusion during delivery and $\mathbf{R h}$-sensitisation of the newborn. Lancet, 1, 46.

Mann, H. B., and Whitney, D. R. (1947). On a test of whether one of two random variables is stochastically larger than the other. Annals of Mathematical Statistics, 18, 50-66. 
Nisonof, A., Wissler, F. C., Lipmann, L. N., and Woernley, D. L. (1960). Separation of univalent fragments from the divalent rabbit antibody molecule by reduction disulfide bonds. Archives of Biochemistry and Biophysics, 89, 230-244.

Ramos de Almeida, J. M., and Rosado, L. (1972). Rh blood group of grandmother and incidence of erythroblastosis. Archives of Disease in Childhood, 47, 609-612.

Taylor, J. F. (1967). Sensitisation of Rh-negative daughters by their Rh-positive mothers. New England Journal of Medicine, 276, 547-551.

Woodrow, J. C. (1974). Effectiveness of $\mathrm{Rh}$ prophylaxis. Haematologia (Budapest), 8, 281-290.

Correspondence to Dr C. M. Stern, Department of Paediatrics and Neonatal Medicine, Hammersmith Hospital, Du Cane Road, London W12 0HS.

\title{
Fetal growth and parental consanguinity
}

\author{
J. R. SIBERT, MALATI JADHAV, AND S. G. INBARAJ
}

Christian Medical College, Vellore Tamil Nadu, South India

SUMMARY Anthropometric measurements made on 322 newborn infants in South India were related to parental consanguinity. Uncle-niece and firstcousin marriages were common and the average coefficient of inbreeding was as high as 0.0329 . The measurements (weight, length, head circumference, and triceps and subscapular skinfold thicknesses) of the uncle-niece groups (52 infants) were smaller than those of the first-cousin group (61 infants) which in turn were smaller than the nonconsanguineous group (196 infants). Statistical significance $(\mathrm{P}<0 \cdot 01)$ was only recorded between the weights of the three groups (means 2650.4, 2794.1, and $2833.8 \mathrm{~g}$ ) and between the lengths of the uncle-niece group and the nonconsanguineous group (means 46.92 and $47.79 \mathrm{~cm}$ ). There were no social class or residential differences between the groups. We conclude that there are likely to be recessive genes present in the population, slightly retarding fetal growth.

There are probably more consanguineous marriages in South India than in any other large nonisolated population in the world. Uncle-niece and first-cousin marriages are favoured for a variety of cultural reasons, including keeping property in the family. In the course of a study to assess the effect of maternal nutrition on infant anthropometric measurements (Sibert et al., 1978), we thought it valuable to assess the effect of parental consanguinity on fetal growth.

\section{Material and methods}

Mothers and their babies were studied at two hospitals in Vellore, Tamil Nadu, South India: the
Christian Medical College Hospital and the Government Pentland Hospital. All singleton infants over 37 weeks' gestation born on unselected days were studied during the period August to October 1977. As information on gestation was inaccurate in a significant number, all infants were assessed by the method of Parkin et al. (1976). All but 8 of them were $>39$ weeks' gestation. None of the mothers smoked.

Interns from the Child Health Department assisted with Tamil translation. Information was collected on the relationship between the parents. Information was also collected on the social class of the father, whether the parents paid for the care, and whether the family lived in an urban or rural area. Birthweights of the infants were recorded by midwives on beam scales. Anthropometric measurements were made by one of us (J.R.S.) within 36 hours of birth. Crown-to-heel length was measured by Cardiff neonatometer, and occipito-frontal head circumference by paper tape measure. Infant skinfold thickness was measured by a Holtain caliper (reading to $0.1 \mathrm{~mm}$ ) at the left triceps and subscapular sites using the methods of Oakley et al. (1977).

In the course of the study one stillborn child of first-cousin parents with a form of achondrogenesis was noted but not included in the study. One living microcephalic child of uncle-niece parents was included.

\section{Results}

322 infants were studied. The relationship of their parents is shown in Table 1 . Over $39 \%$ of the children had consanguineous parents. The average coefficient of inbreeding was 0.0329 . Of particular note was the 